\title{
The tool supporting decision making process in area of job-shop scheduling
}

\author{
Justyna Trojanowska $^{1}$, Maria Leonilde Rocha Varela ${ }^{2}$, Jose Machado ${ }^{3}$ \\ ${ }^{1}$ Poznan University of Technology, Chair of Management and Production Engineering, 3 \\ Piotrowo Street, 60-965 Poznan, Poland \\ ${ }^{2}$ Department of Production and Systems, School of Engineering, University of Minho, \\ Guimarães, Portugal \\ ${ }^{3}$ Department of Mechanical Engineering, School of Engineering, University of Minho, \\ Guimarães, Portugal \\ justyna.trojanowska@put.poznan.pl, leonilde@dps.uminho.pt,jmachado@dem.uminho.pt
}

\begin{abstract}
Today most manufacturing companies from machine building industry are operating in single unit or short-run production which is very complex in terms of decision making processes in production planning area. The difficulty in decision making in the area of scheduling is caused by the necessity of analysing multiple factors and evaluating various scheduling options due to numerous criteria. The article presents the author's tool supporting decision making in the area of job-shop scheduling. The tool introduced in the article enables scheduling based on author's priority rule allowing maximum usage of the most loaded resource (known as critical resource), which determines efficiency of the production system. The tool has been designed and verified as a part of $\mathrm{PhD}$ dissertation research.
\end{abstract}

Keywords: job-shop scheduling, decision making process, interactive application

\section{Introduction}

In contemporary world efficiency of manufacturing companies depends not only on production resources available, but also on how well they are used. The problem of using resources the right way is strictly connected to the problem of scheduling production flow. The fact that there are numerous external as well as internal factors influencing production processes makes production scheduling a very complicated issue. Available literature analysis shows that the scheduling problem is one of the most important and complicated problems which has been known as NP-hard and very challenging combinatorial optimization problem since 1950s [1,2] in machine scheduling. With such high complexity of the problem and in keeping with goal criterion which usually is to minimize the time of every operation in a given process it is difficult to find acceptable solution [3] and in most cases an optimum solution cannot be found in reasonable time [4]. 
Today most manufacturing companies from machine building industry are operating in single unit or short-run production which is very complex in terms of decision making processes in production planning area. Range of manufactured products in single unit as well as in short-run production is usually very wide and very unstable at the same time. It is very difficult to predict demand and probability of spreading potential orders over time in advance. On top of that, average time frame from the moment an order is placed to its completion gets shortened $[5,6,7]$. Decisions made in the production planning area relate to balancing manufacturing capacity in terms of quantities, quality, delivery dates and costs of production with customer's requirements. The necessity of analysing numerous factors causes manufacturing companies to use tools helping with decision making in the area of scheduling processes.

\section{Job-shop scheduling}

The first function of business management is planning, which is based on an optimal development of work time and resources [8]. Production planning is done as part of a hierarchical planning process, where the production plan is cascaded down to a more detailed production schedule. The objective of scheduling is to schedule or sequence production tasks, in order to minimize a certain performance measure of customer satisfaction [9].

Scheduling algorithm is selected based on production system characteristic, set of orders to be executed and on encountered constraints. Among scheduling algorithms available in literature on the subject there are two types of scheduling systems: simple and complex. The simple scheduling system is described as single-machine scheduling and parallel-machine scheduling, while the complex system is described with the use of flow-shop scheduling, job-shop scheduling and open-shop scheduling. Numerous scientific publications concerning production tasks prove that job-shop scheduling problems are a current research problem.

Job-shop scheduling problem consists of a finite jobs set, $\mathrm{Ji}(\mathrm{i}=1,2, \ldots, \mathrm{n})$ to be processed on a finite machine set $\operatorname{Mk}(\mathrm{k}=1,2, \ldots, \mathrm{m})$ [10]. According to its production routine, each job is processed on machines with a given processing time, and each machine can process only one operation for each job [11]. Job-shop scheduling can be thought of as the allocation of resources over a specified time to perform a predetermined collection of tasks [12]. Researchers developed several methods to deal with the job-shop scheduling problem. Scheduling problem solving methods can be divided based on type of generated solution into exact methods and approximation methods.

Scheduling problem solving exact algorithms can be used on condition that the system structure is defined, certain task types and certain constraints are defined. The general approach of these methods is to consider the problem in its total system form of scheduling $n$ jobs on $m$ machines. In the literature on the subject exact algorithms are solved with the use of mathematical programming. Mathematical programming is an optimization problem with conditions constraining decision making and a goal function being a decision making evaluation criterion. There are a few methods of 
mathematical programming, such as: partial enumeration, linear programming, integer programming, dynamic programming, branch and bound, branch and dominate [1315]. Exact methods of scheduling problem solving are applicable in a small group of defined problems, where every solution can be assessed. With the increase of complexity of a problem, waiting for solution time is extended and a need to use high computing powers machines arises.

Approximation methods, also known as heuristic methods, do not guarantee finding optimum solution, however, they allow finding acceptable solution in a shorter time that exact algorithms. Shorter time needed for finding solution causes that these methods are used in real production systems, where planning multiple complex manufacturing orders with numerous constraints are needed. In the literature on the subject the following heuristic methods can be found $[13,16]$ :

- local search methods, e. g. ant colony optimization or tabu search,

- evolutionary methods, e.g. genetic algorithm or differential evaluation,

- constructive methods, e.g. priority despatch rules.

The above methods are widely described in literature. The solution presented in this article is one of heuristic methods and is based on priority rules.

Priority rules indicate how to assign a specific job to a specific machine at a given time, when a machine becomes available for process [17-20]. Literature [21,22] classified over 100 priority rules.

During scheduling process, the major issue is choosing appropriate priority rules that will help achieve projected criterion. There are multiple studies comparing how priority rules work in job-shop scheduling [22-24]. For example, minimizing manufacturing process cycle criterion is best achieved with the use of the shortest operation time rule and with the minimal sum of weighted task time.

Scheduling quality measure is represented by goal function created on the base of evaluation criterion. Main criteria of scheduling evaluation are completion times and delivery times parameters. Most common scheduling evaluation criteria are [6,22,25-27]:

- minimizing total manufacturing time, known as minimum makespan $\mathrm{C}_{\max }$

- minimum average makespan, $\mathrm{C}_{\mathrm{s} r}$

- minimizing maximum flow time, $\mathrm{J}_{\max }$

- minimizing maximum delay, $\mathrm{L}_{\max }$

- minimizing average delay, $\mathrm{L}_{\text {śr }}$

- maximum delay, $\mathrm{T}_{\max }$

- average delay, $\mathrm{T}_{\text {śr, }}$

- maximum flow time, $\mathrm{F}_{\text {max }}$

- average flow time, $F_{\text {śr. }}$

Newest literature sources on job-shop scheduling have been collected in studies $[14,28]$, in which the authors research problem solving methods paying special attention to their influence on scheduling evaluation criteria.

Job-shop scheduling problem and adopted building schedules criteria have been described in [29-31]. Due to the large number of criteria to be considered in scheduling problem, it is recommended to used methods supporting decision-making, which effectiveness is proven in numerous publications [32-40]. Useful tool helping decision making in the area of scheduling is simulation. Simulation can be applied to many aspects of manufacturing systems [41]. In job-shop scheduling the simulation of 
dispatching rules and the assessment of the effect of different rules on the shop's ability to meet delivery dates and utilize the machines. The first application of simulation was computer simulation studies of different priority rule have been carried out. Today many of such methods are available through integrated scheduling systems. Examples of such systems, available and free to be used through the Internet, include the LEKIN [42], and Lisa [43], among many others.

For example popular LEKIN Software is a tool with the main purpose of introducing the main scheduling theory and demonstrating the capabilities of several scheduling methods [44].

However, author's tool supporting decision making in job-shop scheduling presented in this paper is a computer application allowing generating schedules in accordance with a chosen priority rule and then comparing results with chosen criteria.

\section{An interactive scheduling application}

Developed computer application takes the form of interactive scheduling system for machine environments, which can be used for scheduling tasks in real life manufacturing or in research, as it has an option of generating sets of orders. The generator allows to define quantity of orders in each set and number of production operations in each order. Duration of each production operation and workstation where each operation takes place are chosen with equal probability from a defined set of numbers. However, in case sets of orders are entered into the system individually, it is possible to define every single parameter of production orders.

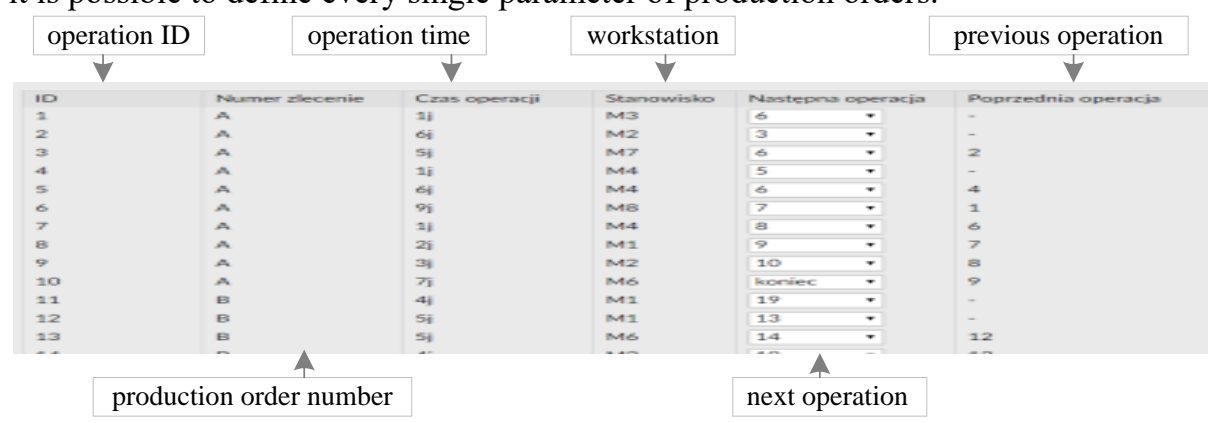

Fig. 1. Set of orders as tabular data

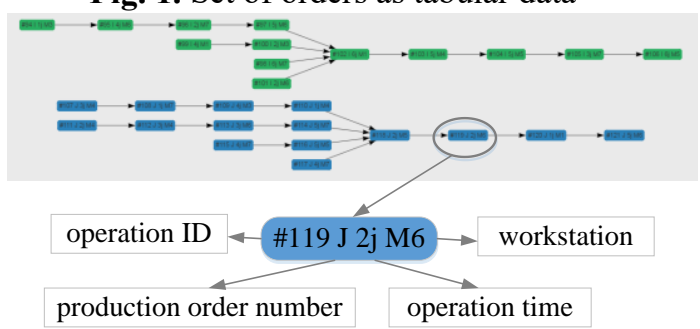

Fig. 2. Set of orders as pictorial data 
Set of production orders is presented as a table (Fig.1) containing:

- production order number

- operation time

- workstation, where an operation is realized

- next operation

- previous operation

and graphically (Fig.2) presenting the structure of each order.

The application allows to generate a schedule created in keeping with the chosen priority rule:

- Shortest task time (STT), a local and static rule that minimizes average task production cycle [45-47].

- Longest task time (LTT), which maximizes average production cycle as well as average number of tasks waiting in queues. However, for job-shop task set it minimizes average workstation-consumption of operations waiting in queues thanks to the fact that the highly workstation-consuming operations are realised faster [22].

- Shortest processing time (SPT), a local and static rule which minimizes average task production cycle and percentage of delayed tasks in job-shop order sets $[22,48]$.

- Longest processing time (LPT) is a local static rule that has a proven efficiency for production systems with numerous machines and production equipment. LPT also minimizes makespan for simple systems.

- First in first out (FIFO) causes waiting time of operations in queues to extend and, at the same time, extending production cycles times [22]

- Priority rule for the smallest total workstation-consumption of workstation orders from the set of chosen chains of workstation orders realized before the critical resource $(\mathrm{CR})$

Priority rule for the smallest total workstation-consumption of workstation orders from the set of chosen chains of workstation orders realized before the critical resource is the author's priority rule designed for a $\mathrm{PhD}$ dissertation. Critical resource is defined as production system resource, which due to work load in job-shop set of production orders determines the efficiency of the whole production system. The superior characteristic of the critical resource among all production workstations is the highest labour-hour load. The designed priority rule demands that from all waiting orders the one with the smallest total workstation order realization time of orders in given chains is chosen.

Own research showed that applying the priority rule for the smallest total workstation-consumption of tasks in the set of chosen chains of operations realized before the critical resource maximizes the usage of the critical resource, which leads to shortening of the average time of realization of a production order set.

The result of scheduling for each of the chosen priority rules is generated graphically as schedule (Fig.3) and as tables containing information concerning:

- order number,

- order start time ,

- order end time,

- total time of an operation in a certain order,

- time of a machine work load start, 
- time of a machine work load end,

- total machine working time,

- total time of machine pauses.

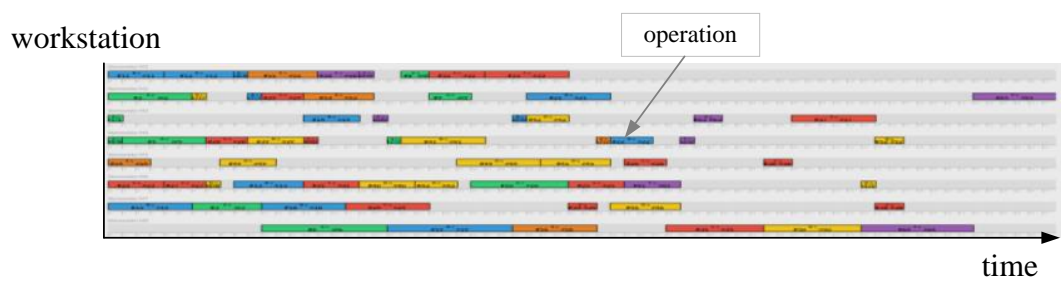

Fig.3. Results presented graphically

Collective results concerning scheduling developed for a given set of production orders in keeping with all available in the application priority rules are presented in the form of a table in spreadsheet MSExcel (fig.4). The table contains information concerning makespan $\left(\mathrm{C}_{\max }\right)$, critical resource work load (wCR) and the amount of work in progress (WIP). Decision-maker gives validity all criteria by determining their weights. The weights can be from 1 to 5 . The application create the ranking takes into account all the criteria simultaneously.

\begin{tabular}{|c|c|c|c|c|c|c|c|}
\hline & & \multicolumn{6}{|c|}{ priority rules } \\
\hline & weight & STT & LTT & SPT & LPT & $\mathrm{FFO}$ & $\mathrm{CR}$ \\
\hline $\mathrm{C}_{\max }$ & 5 & 35 & 38 & 37 & 42 & 45 & 32 \\
\hline $\mathrm{wCR}$ & 2 & 10 & 14 & 11 & 12 & 17 & 8 \\
\hline WIP & 3 & 20 & 18 & 25 & 19 & 20 & 20 \\
\hline & $C_{\text {nave }}$ & 175 & 190 & 185 & 210 & 225 & 160 \\
\hline & $\mathrm{wCR}$ & 20 & 28 & 22 & 24 & 34 & 16 \\
\hline & WP & 60 & 54 & 75 & 57 & 60 & 60 \\
\hline & total & 255 & 272 & 282 & 291 & 319 & 236 \\
\hline & ranking & 2 & 3 & 4 & 5 & 6 & 1 \\
\hline
\end{tabular}

Fig.4. Spreadsheet

The application helps production planner to make decisions in choosing the best schedule for a certain set of orders in keeping with chosen criteria. The possibility of manually modifying weights of each criterion of evaluation makes the application versatile and allows it to be used in a variety of production conditions. The versatility of the application is also proven by the fact that the critical resource can appear multiple times and at any stage of technological process in the structure of a given production order. It is assumed though that the operation realized with the use of the critical resource must not be repeated between the first and the last operation of the same path. Currently works on expanding the application's capabilities with the module allowing rescheduling are being conducted. 


\section{Conclusion}

The tool supporting decision making introduced in this article has been designed as a part of research for a PhD dissertation at Poznan University of Technology. The tool was preliminary implemented in three manufacturing companies in Greater Poland area. The companies confirmed the efficiency of the described tool in supporting decision making in the area of production scheduling.

The application is also successfully used for research in the area of job-shop scheduling. Currently works are conducted on defining rules for scheduling conversion and adding a rescheduling module to the already designed application.

\section{Ac1knowledgment}

This work has been supported by COMPETE: POCI-01-0145-FEDER-007043 and FCT - Fundação para a Ciência e Tecnologia within the Project Scope: UID/CEC/00319/2013.

\section{References}

1. Zhang, R., Song, S., Wu, C.: A hybrid artificial bee colony algorithm for the job shop scheduling problem. International Journal of Production Economics, 141, pp. 167-178 (2013)

2. Lenstra, J. K., Kan, A. H. G. R., Brucker, P.: Complexity of machine scheduling problems. Annals of Discrete Mathematics, 1, pp343-362 (1997)

3. Deepu, P.: Robust Schedules and Disruption Management for Job Shop. Dissertation of Montana State University, Bozeman, Montana (2008)

4. Asadzadeh, L., Zamanifar, K.: An agent-based parallel approach for the job shop scheduling problem with genetic algorithms. Mathematical and Computer Modelling, 52, pp. 19571965 (2010)

5. Hamrol, A., Strategies and practices of efficient operation. LEAN SIX SIGMA and other [in Polish]. PWN, Warsaw (2015)

6. Knosala, R.: Computer aided business management (in Polish). Polish Economics Publishers, Warsaw (2007)

7. Zawadzki, P., Żywicki, K.: Smart product design and production control for effective mass customization in the Industry 4.0 concept. Management and Production Engineering Review, Vol. 7, No 3, September 2016, pp. 105-112 (2016)

8. Ulewicz, R., Jelonek, D., Mazur M.: Implementation of logic flow in planning and production control. Management and Production Engineering Review, Volume 7, Number 1, pp. 89-94 (2016), DOI: 10.1515/mper-2016-0010

9. Hadidi, L.A., Al-Turki, U.M., Rahim, A.: Integrated models in production planning and scheduling, maintenance and quality: a review. Int. J. Industrial and Systems Engineering, Vol. 10, No. 1, pp.21-50 (2012)

10.Geyik F., Cedimoglu I.H.: The Strategies and parameters of tabu search for job-shop scheduling. Journal of Intelligent Manufacturing, 15, pp.439-448 (2004) 
11.Chen, J. C., Wu, C.C., Chen, C.W., Chen, K.H.: Flexible job shop scheduling with parallel machines using genetic algorithm and grouping genetic algorithm. Expert Systems with Applications, 39, pp. 10016-10021 (2012)

12.Surekha, P., Sumathi, S., Solution to the job shop scheduling problem using hybrid genetic swarm optimization based on $(\lambda, 1)$-interval fuzzy processing time. European Journal of Scientific Research, 64(2), pp. 168-188 (2011)

13.Arisha, A., Young, P., El Baradie: Job Shop Scheduling problem: an Overview. In: International Conference for Flexible Automation and Intelligent Manufacturing FAIM 01, Dublin, Ireland, pp.682-693 (2001)

14.Calis, B., Bulkan S.: A research survey: review of AI solution strategies of job shop scheduling problem. Journal of Intelligent Manufacturing, Vol. 26, Issue 5, pp. 961-973 (2013)

15.Lee, C.Y., Piramuthu, Tsai, Y.K.: Job Shop Scheduling with Genetic Algorithm and Machine Learning. Int. Journal of Production Research, Vol. 35, No. 4, pp 1171-91 (1998)

16.Pinson, E.: The Job Shop Scheduling Problem: Concise survey and some recent Developments. In: P. Chretienne, P., Coffman Jr., E.G., Lenstra, J.K., Lim Z. (eds.) Scheduling Theory and its applications. John Wiley \& Sons Ltd. (1995)

17.Gere, W. S. Jr.: Heuristics in Job-Shop Scheduling. Management Science, vol 13, 167-190 (1966)

18.Giffler, B., Thompson, G. L.: Algorithms for Solving Production Scheduling Problems, Operations Research, 8(4), pp.487-503 (1960)

19.Rowe, A. J., Jackson, J. R.: Research Problems in Production Routing and Scheduling. Journal of Industrial Engineering, vol 7, 116-121 (1956)

20.Smith, W. E.: Various Optimizers for Single Stage Production. Naval Research Logistics Quarterly, vol 3, pp. 59-66 (1956)

21.Panwalker, S.S., Iskander, W.: A survey of scheduling rules, Operations Research, vol.25, no.1, January-February (1977)

22.Wróblewski, K.J.: Basics of flow control production [in Polish]. WNT, Warsaw (1993)

23.Banaszak, Z., Jampoliński, L.: Computer-aided modeling of flexible manufacturing systems [in Polish]. WNT, Warszawa (1991)

24.Conway, W.R., Maxwell, L.W., Miller, L.W.: Theory of Scheduling. Addison-Wesley Publishing Company, London (1967)

25.Kuhpfahl, J.: Job Shop Scheduling with Consideration of Due Dates. Springer (2015)

26.Ross, E.H.P., Corne, D.: Evalutionary scheduling: A review, Genetic Progremming and Evolvable Machines, Vol.6, pp.191-220 (2005)

27.Senger, Z.: Production flow control [in Polish]. WPP, Poznań (1997)

28.Burgy, R.: A neighborhood for complex job shop scheduling problems with regular objective. Les Cahiers du GERAD (2016)

29.French P., (1982), Sequencing and scheduling: an introduction to the mathematics of the job shop, John Wiley\&Sons, New York

30.Pawlak M., (1999), Evolutionary algorithm as a tool for production scheduling [in Polish]. PWN, Warszawa (1999)

31.Skołud B.: Operational management. Production in small and medium-sized enterprises [in Polish]. WPŚ, Gliwice (2006)

32.Arrais-Castro, A., Varela, M., Putnik, G., Ribeiro, R., Dargam, F.: Collaborative negotiation platform using a dynamic multi-criteria decision model. International Journal of Decision Support System Technology. Vol. 7, Issue: 1, pp. 1-14 (2015) DOI: $10.4018 /$ ijdsst.2015010101

33.Diering, M., Hamrol, A., Kujawińska, A.: Measurement system analysis Combined with Shewhart's Approach. Key Engineering Materials, Vol. 637, pp 7-11, CTrans Tech Publications, Switzerland, (2015) DOI:10.4028/www.scientific.net/KEM.637.7 
34.Kluczek, A.: Application of multi-criteria approach for sustainability assessment of manufacturing processes. Management and Production Engineering Review, Volume 7, Number 3, pp. 62-78 (2016), DOI: 10.1515/mper-2016-0026

35.Kłos S., Implementation of the AHP method in ERP-based decision support systems for a new product development, In: Dregvaite G., Damasevicius R. (eds.) Information and software technologies: 21st International Conference, ICIST 2015, Springer International Publishing Switzerland, pp. 199--207 (2015), DOI: 10.1007/978-3-319-24770-0_18

36.Kłos, S., Patalas-Maliszewska, J.: Throughput analysis of automatic production lines based on simulation methods. In: Jackowski K., Burduk, R., Walkowiak, K., Woźniak, M., Yin H. (eds.) Intelligent data engineering and automated learning - IDEAL 2015, Springer International Publishing Switzerland (2015) DOI: 10.1007/978-3-319-24834-9_22

37.Kolinski, A., Śliwczyński B.: IT support of production efficiency analysis in ecological aspect. In: Golinska P., Kawa A. (eds.) Technology Management for Sustainable Production and Logistics, Springer Verlag, Berlin, p. 205-219 (2015) DOI: 10.1007/978-3-642-33935611

38.Kujawińska, A., Rogalewicz, M., Diering, M.: Application of expectation maximization method for purchase decision-making support in welding branch. Management and Production Engineering Review, Vol. 7, No. 2, pp. 29 -33 (2016) DOI: 10.1515/mper-20160014.

39.Kujawinska, A., Rogalewicz, M., Diering, M., Piłacińska M., Hamrol A., Kochański A.: Assessment of ductile iron casting process with the use of the DRSA method. Journal of Mining and Metallurgy Section B-Metallurgy, Vol. 52, Issue 1, pp.25-34 (2016), DOI:10.2298/JMMB150806023K.

40.Starzyńska B., Hamrol A.: Excellence toolbox: Decision support system for quality tools and techniques selection and application. Total Quality Management \& Business Excellence, 24:5-6, pp.577-595 (2013) DOI: 10.1080/14783363.2012.669557

41.Pandilov, Z., Milecki, A., Nowak, A., Górski, F., Grajewski, D., Ciglar, D., Mulc, T., Klaić, M.: Virtual Modelling And Simulation Of A CNC Machine Feed Drive System. Transactions of FAMENA, vol. 39 iss. 4, pp. 37--54(2015)

42.Pinedo, M.: Scheduling: theory, algorithms, and systems. Springer (2012)

43.Andresen, M., Bräsel, H., Engelhardt, F., Werner, F.: LiSA-a Library of Scheduling Algorithms: Handbook for Version 3.0: Univ. Fak. für Mathematik (2010)

44.Pinedo M., Operations scheduling with applications in manufacturing and services, McGraw-Hill (1998)

45.Conway, R.W.: An Experimental Investigation of Priority Assignment in a Job Shop. Rand Corporation Memorandum, RM-3789-PR, Santa Monica (1964)

46.LeGrande, E.: The Development of a Factory Simulation Using Actual Operating Data. Management Technology, vol.3, no.1, pp.1-19 (1963)

47.Nelson, R.T.: Simulation of Labor Efficiency and Centralized Assigment in a Production Model. Management Science, vol.17, no.2 (1970)

48.Baker, K.R., Dan Trietsch, D.: Principles of Sequencing and Scheduling. John Wiley\&Sons, New Jersey (2009) 